\title{
Heat and mass transfer modeling for fruit drying: a
} review

\begin{abstract}
In this review, coupled heat and mass transfer phenomena (drying) is discussed .Drying is an effective method for fruit storage/preservation. Drying could retain quality end products, which is challenging, because all fruits are variable in structure, so, heat and mass transfer modeling (operating parameters) is a useful technique to deal with it. This can only be done by selecting the right type of drying equipment and understanding the science behind the drying process including thermal properties of fruit. Drying process have many effects on different heat sensitive fruits components and equipment (sensors etc.) as well which result into increase in maintenance cost, diffusion rate goes to critical limits etc. Because, selection of an appropriate drying method and equipment is most important regarding product quality and its economic value. Modeling of a drying process considering different drying parameters and their effects on final quality of products and economic importance are also discussed here. We should have knowledge about the drying mechanics. So, that knowledge of heat and mass transfer process for fruit drying helps to identify best operating conditions and saves the maximum amount of energy.
\end{abstract}

Keywords: sensors, oxidation, shelf life, perishable, rehydration
Volume 7 Issue 3 - 2019

\author{
Javed Iqbal M,Waseem Akbar M, Rawal Aftab, \\ Ibrar Younas, Umer Jamil \\ Department of Food Science and Technology, University of \\ Agriculture Faisalabad, Pakistan
}

Correspondence: Javed lqbal M, Department of Food Science and Technology, National Institute of Food Science and Technology, University of Agriculture Faisalabad, Pakistan, Tel +923316837033, Email Muhamedjavediqbal45@gmail.com

Received: July 04, 2019 | Published: August 22, 2019

\section{Introduction}

Food is the necessity for mankind as it provides energy, growth, and repair to the body. ${ }^{1}$ Fruit is an agricultural commodity and most of the agricultural commodities are seasonal. Fruits are present in bulk amount during their season, but during the offseason, this seasonal fruit is unavailable because it gets wasted due to improper storage techniques. About $40 \%$ of the fruits production in Pakistan was wasted due to improper handling and preservation techniques. ${ }^{2}$ Fruit production in Pakistan in 2016-17 is 5,685,000tons and 440,000tons were exported and 2,274,000tons get wasted. ${ }^{2}$ To make food secure one should reduce post-harvest losses. Fruits get wasted due to improper harvesting, transportation, processing, and preservation methods. Agricultural products are sometimes categorized on the basis of water contents present in them; perishable, semi-perishable and non-perishable products. These products have different shelf life depends on their perish ability level. ${ }^{3}$ Almost, all the fruits in its raw form are considered as perishable due to the high content of water present $(65-95 \%)$ in them. ${ }^{4}$ Water is major constituent of fruits and after harvesting maturing process of climacteric fruits continues. This water leads the fruits to get spoil due to autolysis and microbial attack. Fruits are decayed due to biochemical reactions, microbial growth, enzymatic activity and proliferation, and water is the factor to do so. ${ }^{4}$ Chemically, fruits get spoiled due to non-enzymatic browning and oxidation. ${ }^{3}$ So, to consume seasonal fruits, one has to protect fruits from these microorganisms. Food security is one of the burning issues of our community. Food insecurity includes many factors and postharvest loses is one of them. Fruit processing is most important regarding as an improvement in agricultural industry, to make the economy of country strong and increase the export and develop new value-added products such as dried fruits are one of them. ${ }^{5}$ Drying is one of the most efficient and economical method for saving food from getting spoiled and to export them in good quality form. For few days fruit can be save according to its shelf life (perish ability value), but after these days sensory parameters like taste, flavor, texture, color degrades and finally, fruit becomes unable to eat. In order to prolong its shelf life for months, dry it by proper means and in a hygienic environment.
Drying is a unit operation that is carried out to preserve fruit, instead of a unit process, which is a chemical process. Drying is the removal of moisture from fruit products up to a certain level and dehydration is the bone-dry condition of that product. Drying is a physical process performs to stabilize fruit as biological changes in fruit lead to deterioration. Cost of transportation decreases and handling becomes easy as its weight and volume reduces, consumption is followed with calculated rehydration.

\section{Objectives of drying}

Drying slows down the microbial and enzymatic activity by lowering water activity. Apple has a water activity of $0.85-0.95$ and drying reduces water activity to about $0.5 .^{2}$ Fruits are dried due to many reasons; to consume seasonal fruits and to export these products in non-production areas of such fruits. Dried fruits enhance the taste of food products when used as food formulations in many food products such as ice creams, frozen desserts, sweets, bakery products, baby foods, jellies, crackers, horseradish, miscellaneous, and sauces etc. Among dried fruits Apples are being used in many products in Pakistan such as custards, pasta, and jellies etc. Noodles which are staple food of some Asian countries ${ }^{6}$ e.g. are mostly found in the market in instant form and all fruits in it are in dried form. Some of the fruits are converted to powder to use an ingredient in food recipes.

\section{Heat transfer}

Temperature difference is the driving force for heat transfer. So, heat transfer exchanges thermal energy from high concentration to low concentration between physical systems. There are three modes of heat transfer namely, conduction, convection, and radiation. Mostly conduction and convection modes are used for drying of fruits. Radiation is a modern technique having high quality dried products but operating costs are very much high which makes it infeasible in developing and underdeveloped countries, however, these techniques are used in developed countries.

Energy in drying is in the form of heat, and heat is the simplest form of energy and travels from hotter to cooler medium. Heat leaving 
away from the system towards surrounding gives the negative heat transfer rates and vice versa. Generally, heat transfer is: $Q=m C_{-} p T$.

Where,

$\mathrm{Q}=$ Heat transfer $\mathrm{KJ}$

$\mathrm{m}=$ Mass of fruit material $(\mathrm{kg})$

C_ $\mathrm{p}=$ Specific heat of the material being dried $\left(\mathrm{kJ} /\left(\mathrm{kg}^{\circ} \mathrm{C}\right)\right)$

$\Delta \mathrm{T}=$ Temperature difference $\left({ }^{\circ} \mathrm{C}\right)$

One important thing to consider is $\mathrm{C}_{\mathrm{B}} \mathrm{p}=\mathrm{C}_{-} \mathrm{V}$ for solids and liquids ${ }^{7}$

Thermal properties of fruit are listed below ${ }^{8}$

\section{Specific heat}

Quantity of heat required to change a unit temperature of unit mass of product, without changing in its original state.

$C_{p}=\frac{Q}{m(T)}$ Its units are $\left[k J / \mathrm{kg}^{\circ} \mathrm{C}\right]$. Specific heat of product is needed in designing of drying equipment and processes. Specific heat is directly proportional to the moisture content of the product. Specific heat can be determined by numerical methods presented by Choi and Okos in 1986. Methods for specific heats determinations are; Method of Mixture, Method of Guarded Plate, Method of Comparison Calorimeter, Adiabatic Agricultural Calorimeter, Differential Scanning Calorimeter (DSC). ${ }^{8}$

\section{Thermal conductivity:}

Quantity of heat is conducted through per unit thickness, per unit time of the product, if two materials having a unit temperature difference.

$W / m^{2}{ }^{\circ}$. Its units are $W / m^{2}{ }^{\circ} \mathrm{C}$. Thermal conductivity is useful in determining heat transfer rates. Thermal conductivity for water at $20^{\circ} \mathrm{C}$ is $0.597 \mathrm{~W} /\left(\mathrm{m}^{\circ} \mathrm{C}\right)$. Dried fruits have lower thermal conductivity values due to the porous structure. Thermal conductivity can also be calculated by Choi and Okos numerical model. Heldman and Singh also developed mathematical models to determine thermal conductivity for anisotropic food products which are direction dependent e.g.: parallel to fibers or normal to fibers slices of mango. Different types of models are also made to calculate thermal conductivity such as; Parallel Model, Series (Perpendicular) Model, Krischer Model, Maxwell-Eucken Model, Kopelman Model. ${ }^{9}$

\section{Thermal diffusivity}

Ratio of thermal conductivity to specific heat and density.

$$
\frac{\text { Heat Conduction }}{\text { Heat Stored }}=\frac{k}{\rho C_{p}}
$$

Its units are $\left(\mathrm{m}^{2}\right) \mathrm{s}$. Thermal diffusivity can be calculated by inserting values of thermal conductivity, specific heat, and density. Density can be calculated from Choi and Okos (1986) mathematical formulas by just inserting the value of the temperature of the product. Methods for determining thermal diffusivity are Indirect Prediction Method, Direct Measurement Method (Dickerson method etc.). ${ }^{9}$

\section{Mass transfer}

Mass transfer is the movement of chemical species from high concentration region to low concentration region and the presence of these two regions are necessary, but fluid flow moves from one location to another and occurs on a macroscopic level. Fluid flow needs pressure difference and mass transfer needs concentration difference as their driving force. Modes for mass transfer are conduction and convection only. Fick's second law for mass transfer is usually studied to understand the mass transfer rate. There are different types of mass transfer conduction (diffusion) namely; ordinary diffusion, forced diffusion, Knudsen diffusion, surface diffusion, Brownian motion and each have their applications for respective products. ${ }^{?}$

\section{Drying process}

Drying is a coupled heat and mass transfer mechanism. There are different types of drying units/machinery used in this modern era. Food Engineers are working very hard to develop more efficient methods for drying of perishable agricultural products that least alter its quality. There are different drying methods and nowadays mostly hot air drying is used, some of the drying methods used are; direct sun drying, solar tunnel dryer, solar augmented drying, freeze drying, microwave drying, vacuum drying, foam mat drying, puff drying, radiant heating dryer, infrared dryer, spray drier, fluidized dryer, Oregon tunnel dryer, de hydro-freezing. ${ }^{2}$ Selection of a suitable drying method is very important for final product quality and operating cost. Some of the drying methods need huge installments and high energy expenses that make them not suitable.

Drying causes nutritional, physical, chemical and sensory changes in fruit that depend on heat and mass transfer parameters. Many compounds in fruits are temperature dependent, due to their heatsensitive properties, an exact amount of heat is provided to avoid quality deterioration of fruits. The efficiency of the drying process is dependent on the internal and external parameters provided to it. Internal parameters include thermo-physical properties, sorptiondesorption characteristics, porosity, density and permeability of the fruit material being dried. External parameters include relative humidity, temperature, and air velocity. ${ }^{10}$

Drying rate and product properties depend on the drying parameters such as temperature, air velocity, and relative humidity provided to it. ${ }^{11}$ Kumar suggested that during the drying of food product both heat and mass are in motion as shown in Figure 1.12

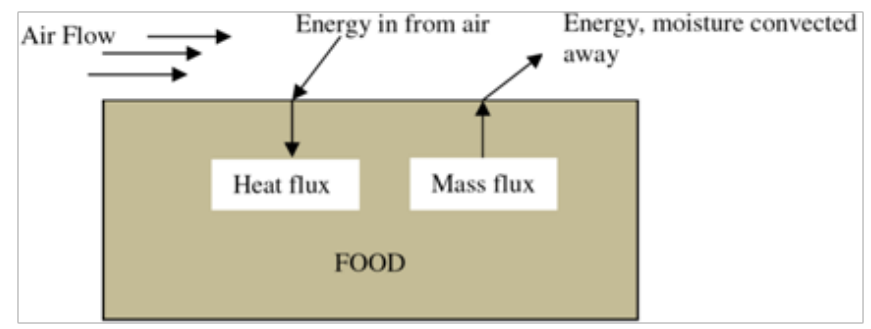

Figure I Shown in drying of food product both heat and mass are in motion.

\section{Modeling of drying mechanism}

Fruit in its biological structure is variable and complex so every fruit needs a different model to dry it by retaining quality, which is challenging. So, modeling and simulation is a useful technique to deal with it. Mathematical model based on heat and mass transfer is used to study the behavior of drying operation. Assumption related to mass transfer parameter i.e., material properties, transport equation, initial and boundary conditions and PDE (Partial Differential Equation) is solved and these models are used to simulate process 
variables. Mathematical model is used to maintain quality and optimize dryer efficiency. Driving force for drying is the temperature difference that causes the moisture to transfer and concentration gradient plays a key role in drying. Coupled heat and mass transfer approach is used for mathematical modeling. ${ }^{11}$ Mathematical model for heat and mass transfer mostly developed based on Fick's law and Fourier law, theoretical and empirical models are used now-adays. ${ }^{7}$ Different mathematical models are made for modeling of drying process (theoretical models etc.). Software such as CFD (Computational Fluid Dynamics), COMSOL Multi-physics is mostly used for simulation.

Mass
transfer Concentration
coefficient difference
Mass convection
\[ \dot{m}_{\text {conv }}=h_{\text {mass }} A_{s}\left(C_{s}-C_{\infty}\right) \]
Heat convection
Heat $\quad Q_{\text {conv }}=h_{\text {conv }} A_{s}\left(T_{s}-T_{\infty}\right)$
transfer demperature
coefficient
eneral steps to select or design the needed type of
ryer

a. Feasibility study of the dryer

i. Dryer for the subject product

ii. Operating parameters

iii. Economic analysis of the dryer etc.

b. Design of dryer using software (solid works, auto CAD etc.)

c. Simulation of a dryer in some software (COMSOL Multiphysics, Computational Fluid Dynamics, Solid works)

d. Fabrication of the dryer

i. Material of development (Food contacting material should be food grade e.g.: Stainless Steel 304, Stainless Steel 316L)

ii. Equipment specifications (dimensions of sections etc.)

e. Testing and evaluation of the dryer

f. Size reduces sample, plastic coating on samples etc.

g. Fruit samples dried under operating parameters

h. Check temperature, humidity by using sensors and calculate weight loss after constant times

i. Quality (sensory, proximate etc.) analysis comparing with other drying methods

j. Simulation of the drying/dried fruit (COMSOL Multi-physics, CFD etc.)

k. Cost analysis on weight basis; for $1 \mathrm{~kg}$ (Economic analysis)
Graphical illustration and statistical analysis of the fruit being dried, using statistical software

1. Mathematical modeling of heat and mass transfer process parameters

i. Modeling by governing equations (inlet and outlet conditions, assumptions, heat transfer equations, mass transfer equations, transport equation, initial and boundary conditions, flow ability, material properties)

ii. Heat and mass transfer modeling and its validation (Analysis)

These objectives should be covered during drying process performance: Figure 2

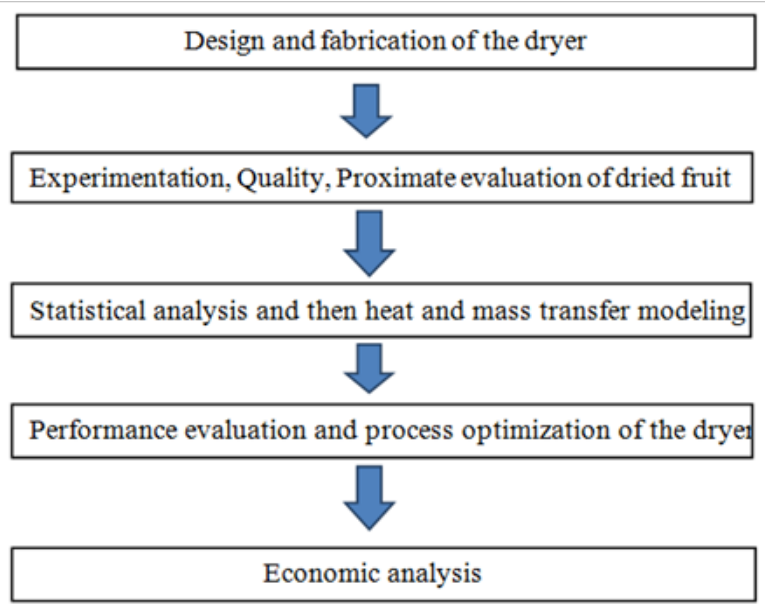

Figure 2 Main steps for developing effective drying process are as follows.

\section{Literature review}

Corrales et al., conducted heat and mass transfer analysis of mango fruit by numerical method. Dryer consists of a tray, heat exchanger using a resistance coil and a drying chamber. Air velocity, air humidity was fixed and the temperature was controlled via sensors installed at inlet and outlet points of the air passage. A K-type thermocouple measures sample temperature. All its components are connected to a digital system to control the process. Ataulfo mango selection considerations is its organoleptic properties, handling resistance, fiber content, sugar content, aroma, for this experimentation. An absence of stability, color, and size was considered. Washed mangoes were kept for $24 \mathrm{~h}$ in a room at a temperature of $24 \pm 3^{\circ} \mathrm{C}$. Moisture content $83.5 \%-85.2 \%$, TSS $13.2-22^{\circ}$ Brix mango slices with $40 \mathrm{~mm}$ long, $15 \mathrm{~mm}$ wide, and thickness of $2,3,4$, and $5 \mathrm{~mm}$ by using slicer equipment and 5 out of 6 sides of mango slices were covered with a plastic film. To check the water effective diffusion, parallel to fibers and normal to fibers shapes of mango were cut. Moisture diffused through only one side (upper side) which was uncovered. During drying, temperature levels were $50^{\circ} \mathrm{C}, 55^{\circ} \mathrm{C}, 60^{\circ} \mathrm{C}, 65^{\circ} \mathrm{C}$ and $70^{\circ} \mathrm{C}$, relative humidity $15 \pm 2 \%$ with $0.2 \%$ air velocity and $13.2-22^{\circ} \mathrm{Brix}$ maturity level. Firstly, from experimental results, it was concluded that drying time and temperature had an inverse relation. Secondly, with $1 \mathrm{~mm}$ increase of thickness, reduced $4.5 \%$ drying rate. Thirdly, moisture diffusion also depends on the maturity level of mango pulp. With more maturity, pulp become viscous and needed more energy to escape from the pulpy juice. The drying for mango is slow inside the slice as compared to boundary layer because of higher moisture 
gradient. Fick's second law and Fourier law were used for numerical calculations. The activation energy was calculated as $23.45 \mathrm{KJ} / \mathrm{Kmol}$ , effective diffusivity $4.41 \times ? 10 ?^{(-10)}-5.95 \times ? 10 ?^{(-10)} m^{2} ?(s$,$) and$ moisture diffusivity $19.40 \times 10^{(-10)}-1.04 \times 10^{(-9)} \mathrm{m}^{2} \mathrm{~s} \cdot .^{13}$

El-Amin Omda Mohamed Akoy et. al., An experiment was conducted to check the drying kinetics and changes in the color of mango slices, when dried under different temperatures. Fresh mangoes were kept in a room at $25 \pm 2{ }^{\circ} \mathrm{C}$ at $50 \%$ relative humidity for 5 days. Mangoes were washed, peeled, and then size reduced to slices by using a slicer with $3 \mathrm{~mm}$ thickness and $50 \mathrm{~mm}$ diameter. Cross flow dryer was used which consisted of a centrifugal fan, drying chamber, temperature control unit, and a heating unit. Convective air drying at $1.5 \mathrm{~m} / \mathrm{s}$ air velocity, $135^{\circ} \mathrm{C}$ temperature, $2 \mathrm{~h}$ time and moisture content of sliced mangoes $82.5 \%(\mathrm{wb})$. Weight loss determination after every 30 minutes. At the end of drying is when $9 \%$ moisture content $(\mathrm{wb})$ was achieved, determined by weight loss formula. Quality parameters such as; color, rehydration ratio were evaluated. Firstly, the color was measured via Chroma meter and compared with the color shade of fresh mango pulp which was considered as a standard. Rehydration ratio was calculated by the AOAC method. $5 \mathrm{~g}$ of dried mango was dip in $50 \mathrm{ml}$ of distilled water for 30-60minutes. After filtration of that rehydrated pulp, the filtrate was weighted and the rehydration ratio was calculated by inserting values in a formula. Finally, it was concluded that drying time changes fruit quality and color. Optimum drying temperature for mango slices were $80^{\circ} \mathrm{C} .{ }^{14}$

Caparino et al. ${ }^{13}$ the research was conducted to check the water diffusion coefficient of mangoes at different maturity stages. Mango (Hilacha variety) of half-ripe and green ripened stage mangoes were washed, peeled, and then sliced. Slices of $34.4 \times 10^{(-3)} \mathrm{m}$ long, $34.4 \times 10^{(-3)} \mathrm{m}$ wide, $3.0 \times 10^{(-3)} \mathrm{m}$ thick by coring (process of eliminating seed from its pulp). Air drier used consisted of the drying chamber, fan, and a heat exchanger using resistance coil. The heat exchanger heated dry air to required dry bulb temperature. Mango slices were placed in a tray which was hanged in the drying unit and attached to a weight balance. Heated air flows from top to bottom of the dryer. Air velocity of $1.80 \mathrm{~m} / \mathrm{s}, 1.91 \mathrm{~m} / \mathrm{s}$, the temperature of $50^{\circ} \mathrm{C}$, $60^{\circ} \mathrm{C}, 70^{\circ} \mathrm{C}, 80^{\circ} \mathrm{C}$, air humidity $0.018 \pm 0.001 \mathrm{kgkg}$ of dry air. Weight loss measured after every 10 minutes. The experiment was repeated two times to increase accuracy. Green mango slices had a moisture content of $6.973 \pm 0.112(\mathrm{~kg}$ water $) \mathrm{kg}(\mathrm{db})$ and half ripe mango slices having $6.015 \pm 0.231$ ( $\mathrm{kg}$ water $) \mathrm{kg}(\mathrm{db})$. EMC was calculated ranging from $0.105 \pm 0.008$ ( $\mathrm{kg}$ water $) \mathrm{kg}(\mathrm{db})$ to $0.325 \pm 0.018(\mathrm{~kg}$ water $) \mathrm{kg}$ $(\mathrm{db})$. Water diffusion was the main process there, so Fick's second law for diffusion was applied there. Finally, numerical investigation tells that effective diffusion coefficient for green mango slices at operating temperature $\left(50,60,70,80^{\circ} \mathrm{C}\right)$ and velocity $(1.80 \mathrm{~m} / \mathrm{s}, 1.91 \mathrm{~m} / \mathrm{s})$ is in the range of $1.74 \pm 0.25 \times 10^{(-10)} t o 3.15 \pm 0.07 \times 10^{(-9)} \mathrm{m}^{2} s$ and for half ripe mango slices $2.30 \pm 0.14 \times 10^{(-10)} t o 3.28 \pm 0.21 \times 10^{(-9)} \mathrm{m}^{2} \mathrm{~s}$. Diffusion coefficient for green mangoes at $1.80 \mathrm{~m} / \mathrm{s}$ and $1.91 \mathrm{~m} / \mathrm{s}$ are $22.3 \mathrm{KJ} / \mathrm{mol}$ and $11.4 \mathrm{KJ} / \mathrm{mol}$ respectively. Diffusion coefficient for half ripe mango slices at $1.80 \mathrm{~m} / \mathrm{s}$ and $1.91 \mathrm{~m} / \mathrm{s}$ are $9.3 \mathrm{KJ} / \mathrm{mol}$ and $8.7 \mathrm{KJ} / \mathrm{mol}$ respectively. Research showed that green mango slices are more temperature sensitive as compared to half ripe mango slices because of least development of mango pulp. ${ }^{15}$

Yang tao et al. Study was conducted for the mass transfer modeling and for evaluating the mass transfer modeling for garlic slices. Garlic is known for its medicinal properties and mostly used as a spice for flavoring. Drying of garlic slices should be such that it doesn't destroy garlic sensitive compounds. Many severe changes in fruit compounds and quality parameters were degraded during drying including aroma, texture, color, and most of the heat-sensitive compounds were damaged due to high energy content provided to garlic slices. Shrinkage reduced the rehydration rate. Modern technologies like infrared radiation, pulsed electric field, and high-pressure processing, contacting ultrasound system improved the drying process rate and quality parameters for the product being dried and also reduce the energy requirement. To increase the efficiency of the drying process researchers designed contacting ultrasound system coupled with hot-air convective drying mechanism. Fresh garlic (Allium Sactivum $L$. variety: white) was used with moisture content of $2.04 \pm 0.04(\mathrm{~kg}$ water) $\mathrm{kg}(\mathrm{DM})$ and stored for 5 days at $4^{\circ} \mathrm{C}$. Garlic was peeled and size was reduced to slices shape with $2.04 \pm 0.3 \mathrm{~mm}$ thickness in longitudinal axis. Forced circulating convective oven was coupled with ultrasound equipment of $20 \mathrm{~Hz}$. Electric fan take air from oven and passing through hybrid drier and exiting from top. Stainless steel (food grade) tray $(10 \times 10 \mathrm{~cm})$ was used to contain garlic slices, this plate was connected to piezoelectric ultrasound transducer having 10 $\mathrm{cm}$ diameter. Products dried by coupled ultrasound system, and other methods were compared via quality parameters (determination of shrinkage, color, texture, total phenolic content, organosulfur profile, and thiosulfinate content) of garlic slices. Garlic slices were dried at $50^{\circ} \mathrm{C}, 60^{\circ} \mathrm{C}, 70^{\circ} \mathrm{C}$ and with $216.8 W ? \mathrm{~m}^{2}, 902.7 \mathrm{~W} ? \mathrm{~m}^{2} .1513 .5 \mathrm{~W} ? \mathrm{~m}^{2}$ ultrasound intensities, constant air velocities of $2.5 \mathrm{~m} / \mathrm{s}$. A weighted sample of garlic slices $(2 \mathrm{~g})$ was placed on this stainless steel vibrating tray. Sonication treatment was given for $3 \mathrm{~s}$ with $1 \mathrm{~s}$ interval. Humidity was $16.4 \%$ at $50^{\circ} \mathrm{C}, 10.5 \%$ at $60^{\circ} \mathrm{C}$, and $8.5 \% 70^{\circ} \mathrm{C}$ and triplicate were used for conducting this research. To determine the shrinkage pattern garlic bulbs were sized reduced to $8 \mathrm{~mm}$ cubic shape. Cubic shape garlic bulbs were dried in a convective dryer. Air velocity of $2.5 \mathrm{~m} / \mathrm{s}$ with $70^{\circ} \mathrm{C}$ temperature. After every $20 \mathrm{~min}$ volume and moisture content of garlic bulb was measured. For moisture content measurement AOAC method was used while for volume determination, toluene displacement method was used. Mass transfer modeling was developed using Fick's second law for diffusion. Resistance by external mass transfer and shrinkage of garlic slices were considered to develop diffusion model. Mathematical model was solved in MATLAB (pdepe function) to get results.

Yang tao et al. Garlic slices were evaluated for quality analysis. Drying of garlic slices at $60^{\circ} \mathrm{C}$ and grinded to fine powder. Freeze dryer was also used to dry garlic slices which take $48 \mathrm{~h}$ and then grinded this freeze dried slices. Freeze dried samples, convective dried samples, ultrasound treated samples were compared in a triplicate. Quality analysis includes the determination of garlic fruit compound and effect on them due to drying; determination of phenolics, thiosulfinates, antioxidant capacity, organo-sulfur profile was performed. Thermocouples were used to sense the overheating with a data logger. Increasing the temperature reduced drying time at constant ultrasound intensity to $175 \mathrm{~min}, 105 \mathrm{~min}$, and $85 \mathrm{~min}$ at $50^{\circ} \mathrm{C}$, $60^{\circ} \mathrm{C}$, and $70^{\circ} \mathrm{C}$ respectively. By increased temperature, moisture gradient increased, decreased relative humidity and as a result drying kinetics of the product increased. By varying sonication of ultrasound samples to $216.8 \mathrm{~W} / \mathrm{m}^{2}, 902.7$ and $1513.5 \mathrm{~W} / \mathrm{m}^{2}$ at $50^{\circ} \mathrm{C}$ to $190 \mathrm{~min}$, $175 \mathrm{~min}$, and $130 \mathrm{~min}$ respectively. Applying 1513.5 ultrasonic sonication drying rate were reduced to $48.5 \%$ at $60^{\circ} \mathrm{C}$, and $50 \%$ at $70^{\circ} \mathrm{C}$. Hence, with increased ultrasound intensity drying time also reduced. The results also concluded that the drying rate was directly proportional to energy provided in form of heat, even at constant ultrasonic intensities temperature increase results decrease in drying time. 
Macmanus $\mathrm{CN}$ et al. ${ }^{16}$ Dry three varieties of cocoyam slices namely; Colocasia esculenta (COE) and Xanthosoma sagitti olium (white flesh-NX01, red flesh-NX02) through convective drying mechanism (sun drying and oven drying). Basically, they check retention of vitamin after drying. Heat and mass transfer parameters such as; convective heat and mass transfer coefficient, diffusivity coefficient, activation energy, energy consumption, drying rate, volume shrinkage ratio were also monitored. Cocoyam was sliced. Temperature of $50^{\circ} \mathrm{C}, 60^{\circ} \mathrm{C}, 70^{\circ} \mathrm{C}$, was recorded with humidity of $7.8 \%, 5.1 \%$ and $3.6 \%$ and with a constant air velocity of $0.02 \mathrm{~m} / \mathrm{s}$. Thermocouple was inserted in the product to record temperature inside the slices which was $22^{\circ} \mathrm{C}-22.5^{\circ} \mathrm{C}$. After every 30 minutes weight was recorded to check the moisture loss. For all three varieties of cocoyam slices, the coefficient for mass transfer was in range 1.17973-3.5828 $\mathrm{W} / \mathrm{m}^{2}$ at temperature $50^{\circ} \mathrm{C}, 60^{\circ} \mathrm{C}, 70^{\circ} \mathrm{C}$. $\mathrm{COE}$ showed the highest rate for heat and moisture transfer and the lowest rate was shown by red flesh NXO 2 Vitamin B (riboflavin) showed the highest retention level with $92.25-100 \%$ while thiamine had the lowest retention level with $70.13-82.3 \%{ }^{16}$

\section{Conclusion}

This review article is for drying, which is a simultaneous heat and mass transfer process for the drying of fruits. Fruits due to high water content and heat sensitive compounds in it are difficult to dry, by maintaining quality. Understanding heat and mass transfer process and its parameters are mandatory for the drying process, which minimally affect the sensory and other quality parameters of dried fruit. Calculations for heat and mass transfer greatly help to optimize the efficiency of drying unit, drying rate and as well as reduces energy consumption, it also helps to identify the most appropriate operating conditions.

\section{Acknowledgements}

None.

\section{Conflict of interest}

The author declares there is no conflict of interest.

\section{Funding}

None.

\section{References}

1. Allah Rakha MS. Introduction to food science. In: Mb Tahir Zahoor, editor. Handbook of food science and technology. Faisalabad: University of Agriculture Faisalabad. 2017:19-36.
2. Awan JA. Food scince and technology. Faisalabad, Punjab, Pakistan: Unitech communication; 2018

3. Javed Iqbal M, Aleem A, Hamad R, et al. review paper on foammat drying of fruits and vegetables to develop powders. MOJ Food Processing \& Technology. 2018;6(6):465-467.

4. Syed MI. Post-harvest technology. In: TZ Butt, editor. Handbook of Food Science and Technology. Faisalabad: University of Agriclture Faisalabad. 2017;263-279.

5. Moazzam Rafiq K. Processing of Fruits and Vegetables. In: TZ But, editor. Hand book of Food Science and Technology, Faisalabad: University of agriculture faisalabad; 2017:145-164.

6. Gulia N, Dhaka V, Khatkar BS. Instant noodles: processing, quality and nutritional aspects. Crit Rev Food Sci Nutr. 2014;54(10):1386-1399.

7. Yunus A, Cengel AJ. Heat and mass transfer: fundamentals and applications 4th ed. Oklahoma, USA: SEM. 2014.

8. Paul Singh R, Dennis H. Introduction to food engineering. 4th ed, Elsevier, USA; 2009.

9. Sahin, Serpil, Sumnu, et al. Turkey: physical properties of foods. Springer. 2006

10. Ahmet k, Orhan A, Ibrahim D. Experimental and Numerical Investigation of heat and mass transfer during drying of Hayward kiwi fruits. Journal of Food Engineering. 2008;323-330.

11. Castro AM, Mayorga EY, Moreno FL. Mathematical modeling of convective drying of fruits: A review. Journal of Food Engineering. 2017;223:152-167.

12. Chandan K, Karim A, Joardder MUH, et al. Modeling heat and mass transfer process during convection drying of fruit. Journal of Food Engineering. 2012.

13. Villa-Corrales L, Flores-Prieto JJ, Xamán-Villaseñor JP. Numerical and experimental analysis of heat and moisture transfer during drying of Ataulfo mango. Journal of Food Engineering. 2010;98(2):198-206.

14. Mohamed Akoy EAO, Horsten DV, Luecke W. Drying kinetics and colour change of mango slices as affected by drying temperature and time. Competition for Resources in a Changing World. 2008;1-6.

15. Otoniel C, Nelson B, Carlos A. Water effective diffusion coefficient of mango slices at different maturity stages during air drying. Journal of Food Engineering. 2013;87(4):479-484.

16. Macmanus CN, Cyprian D, Fidelis IA, et al. Heat and mass transfer parameters in the drying of cocoyam slice. Case Studies in Thermal Engineering. 2017;9:62-71. 